D.E.L.T.A., Vol. 15, N. ${ }^{\circ} 2,1999(319-342)$

Debate/Debate

\title{
O Fenômeno da FocalizaÇão e a Interface Fonologia-SintaXe*
}

\author{
Carlos Alexandre Gonçalves (Universidade Federal do Rio de Janeiro)
}

ABSTRACT: The aim of this paper is to describe the strategies of Focalization in Brazilian Portuguese, observing the Syntax-Phonology interface. I defend the independence of Prosody in the materialization of the phenomenon and, for this, I suggest a 'bilateral moderate dissocicionist' connection beetween this two subsystems of Grammar.

Resumo: O objetivo do artigo é descrever as estratégias de focalização no português brasileiro, observando a interface sintaxe-fonologia. Defendo a independência da prosódia na materialização do fenômeno e proposto a relação "dissociacionista moderada bilateral" entre esses dois sub-sistemas da gramática.

KEY-WORDs: Emphasis., Focalisation, Phonology, Syntax.

Palavras-Chave: Ênfase, Focalização, Fonologia, Sintaxe.

0. Introdução

Neste artigo, objetivo refletir sobre o grau de interação entre a Sintaxe e a Fonologia, observando, mais restritivamente, as formas de materialização da 'Ênfase' no português do Brasil. Para tanto, mostro que as propostas de interface no âmbito da Fonologia Não-Linear (cf., p. ex., Selkirk (1984 e 1995), Nespor \& Vogel, (1986 e 1989) e Inkelas \& Zec (1990)) podem ser agrupadas

* Versão revista e ampliada da comunicação Ênfase no português do Brasil: fonologia e sintaxe, apresentada no Colóquio Internacional "A investigação do português em África, Ásia, América e Europa: balanço e perspectivas" (Berlim, março de 1998).

${ }^{1}$ Neste artigo, utilizo o termo Focalização de modo bastante abrangente: forma de pôr em evidência/relevo algum elemento do texto" (cf. Gonçalves, 1997). Considero a Ênfase que requer presença de elementos prosódicos para realçar o item em destaque - uma estratégia de Focalização encontrada nas línguas do mundo. No PB, há três tipos de Ênfase: (a) contrastiva (que está sendo investigada neste trabalho e que freqüentemente se associa ao Foco, nos termos de Jackendoff (1972), Horvath (1986), Freitas (1995) e Frota (1994), entre outros); (b) intensiva (que põe um elemento do texto em evidência através da quantificação); e (c) por silabação (que expressa estados de espírito do falante sobre um assunto, um tema ou um referente). Nesse sentido, 'Focalização' e 'Ênfase' são termos equivalentes neste trabalho. 
sob os seguintes rótulos genéricos: (a) associacionista; (b) dissociacionista radical e (c) dissociacionista moderada.

Constitui propósito do texto verificar que natureza subjaz à manifestação da 'Ênfase' no que diz respeito ao relacionamento Fonologia-Sintaxe: (1) se associacionista ou dissociacionista; (b) se moderada ou radical; e (c) se uni ou bidirecional. Dessa maneira, pretendo observar se a Prosódia prescinde de informações sintáticas para veicular os significados contrastivo e intensivo, predominantes nos casos de Focalização que investiguei (cf. Gonçalves, 1997) ${ }^{1}$. O texto pretende lançar um debate sobre a natureza do relacionamento SintaxeProsódia, de um lado, e sobre o comportamento da Focalização, de outro. Por isso, não aponta para conclusões fechadas acerca do tema, apresentando, antes, um conjunto de reflexões e problemas que podem ser testados em outros fenômenos que, como a Focalização, atuam nos limites entre a Sintaxe e a Fonologia.

\section{As Fonologias não-lineares e a interface Sintaxe-Prosódia}

Nesta seção, procuro tecer comentários gerais acerca da interface Prosódia-Sintaxe no escopo da Fonologia Não-Linear, tomando por base as propostas de tratamento estabelecidas por Selkirk (1984 e 1995), Nespor \& Vogel (1986 e 1989); Liberman \& Prince (1977), Bolinger (1989), Inkelas \& Zec (1990 e 1995) e Goldston (no prelo).

No âmbito da Fonologia atual, podem-se reconhecer três vertentes que buscam analisar o grau de intimidade entre os domínios sintático e fonológico das línguas. Agrupo essas correntes sob os seguintes rótulos genéricos:

(1) dissociacionista radical, centrada na negação categórica de qualquer vínculo entre Sintaxe e Prosódia, tal como concebe Bolinger (1989), para quem as duas "não têm qualquer vocação a se reunirem (...)", uma vez que "a sintaxe precede e é independente da entonação, que se junta a ela posteriormente" (p. 106);

(2) dissociacionista moderada, na qual se considera que os dois níveis organizam o mesmo material de modo autônomo, muito embora não se rejeite a idéia de os constituintes poderem coincidir nos dois planos. Selkirk (1984 e 1995) e Nespor \& Vogel (1986 e 1989), entre outros, defendem um modelo de Gramática que estabelece um módulo prosódico independente, mas relacionado ao sintático; e, por fim,

(3) associacionista, que acredita num verdadeiro "casamento 
monogâmico" entre Sintaxe e Prosódia. Liberman \& Prince (1977) partem do pressuposto de que a árvore métrica reflete, de todo, a constituição sintática. Em outros termos, uma proposta associacionista concebe um componente prosódico gerado a partir do sintático, prevendo correspondência sistemática entre os domínios, sendo a Prosódia sempre traço redundante a acompanhar a configuração sintática.

Uma proposta associacionista não se sustenta, caso se levem em conta as seguintes evidências: (a) informações sintáticas nem sempre são relevantes para a escolha de contornos entonacionais; (b) a configuração melódica não pode ser prevista tendo por base unicamente a configuração sintática, ou seja, não há uma relação de biunivocidade absoluta entre os dois componentes; e (c) uma fatia da sentença pode não ser considerada constituinte sintático e, mesmo assim, portar contorno melódico característico. Esses argumentos, por si sós, já fazem ruir por terra uma visão associacionista sobre a interface Sintaxe-Fonologia.

Se, por um lado, uma abordagem do tipo associacionista não parece adequada, por outro, o relacionamento entre Sintaxe e Prosódia é por demais regular para ser julgado inconsistente e/ou inoperante. Nesse sentido, também se torna contraproducente uma proposta de base puramente dissociacionista, radical, já que a estruturação sintática tende a determinar certos padrões entonacionais.

Callou, Moraes \& Leite (1993: 94-5), por exemplo, ao analisar semelhanças e diferenças entre Deslocamentos à Esquerda e Topicalizações, observam que "a prosódia parece ser traço redundante que acompanha a distinção sintática". Mais adiante, concluem: "é a estrutura sintática que determina os padrões entonacionais e não vice-versa". Em outras palavras, "os padrões prosódicos seriam redundantes, decorrentes de uma estrutura sintática”. Também Freitas (1995: 163), em trabalho sobre índices prosódicos na fronteira de constituintes, mostra que "o foco pode ser sintaticamente motivado e a prosódia tende a sobremarcar essa saliência, atribuindo proeminência a esses constituintes". Um pouco antes (cf. p. 156), a autora afirma que " $a$

\footnotetext{
${ }^{2}$ Estou assumindo aqui a posição de Hirst \& Di Cristo (no prelo), para quem o termo 'Prosódia' deve ser interpretada em sentido lato, incluindo fatores determinados lexicalmente, tais como o acento e o tom. A Entonação se restringe ao que pode ser denominado de "características supralexicais ou pós-lexicais do componente suprassegmental” (cf. p. 7), fazendo referência aos traços tonais que veiculam informação lingüística no nível da sentença.
} 
entonação pode exercer tanto função distintiva quanto delimitadora, apresentando correspondência com o plano sintático-estrutural".

Os fatos acima mencionados conduzem à afirmação de que a Prosódia, de uma forma geral, e a Entonação, como seu subcomponente ${ }^{2}$, não dependem da Sintaxe, de modo direto, mas muitas vezes são dela derivadas. Portanto, as afirmações até então apresentadas autorizam chegar a duas conclusões quanto à relação Sintaxe-Prosódia:

(1) propostas radicais, do tipo associacionista e dissociacionista puramente, não condizem com a verdadeira realidade do relacionamento entre esses dois níveis de análise lingüística; e

(2) em decorrência disso, parece consistente advogar em prol de um modelo de Gramática que considere a Prosódia componente independente da Sintaxe, mas em conexão com ela em maior ou em menor proporção.

Freitas (1995:163), por exemplo, reconhece que embora a Prosódia seja por vezes redundante em termos de estruturação sintática, mantém sua independência, uma vez que (a) nem todos os contrastes sintático-estruturais são traduzíveis pela estrutura prosódica e (b) todos os níveis hierárquicos de organização prosódica podem ser caracterizados independentemente da sintaxe.

Se, por um lado, há relativo consenso quanto à necessidade de a Teoria Linguística, de modo mais geral, e a Fonológica, mais particularmente, reconhecerem um componente prosódico autônomo ${ }^{3}$, por outro, ainda é tema de controvérsia, conforme lembram Vogel \& Kenesei (1990), o nível de influência entre Fonologia e Sintaxe. De fato, Soares (1996: 89) evidencia que ainda permanece a questão de quais informações gramaticais são relevantes para a fonologia, isto é, o quanto ela deve saber da Sintaxe ${ }^{4}$.

Em conseqüência do que se expôs acima, podem-se observar, na literatura, dois pontos-de-vista sobre o grau de intercâmbio na relação Sintaxe-Prosódia: (1) do tipo unidirecional, através do qual somente o componente sintático exerce influência sobre o prosódico (cf. Selkirk, 1984 e 1995) e (2) do tipo

${ }^{3}$ Cf., entre outros, Selkirk (1984) e Nespor \& Vogel (1986).

${ }^{4}$ A questão do acesso da Fonologia à Sintaxe ainda é tema de controvérsia no âmbito da Fonologia Prosódica. Estudos sobre o Radoppiamento Sintattico (cf. Rotenberg, 1978; Napoli \& Nespor, 1979; e Kaisse, 1985, entre outros) deram início ao debate, mostrando que tipo de descrição sintática era necessário para geminar uma consoante em início de palavras dentro de uma sentença. 
bidirecional, versão na qual os dois módulos se influenciam mutuamente (cf. Inkelas \& Zec, 1990 e 1995).

Selkirk (1984: 408) acredita num mapeamento de um-para-muitos entre (i) configuração sintática e (ii) contorno melódico e, com isso, explicita o relacionamento entre as representações de cada um dos níveis, uma vez que a representação fonológica é, em grande parte, sensível à estrutura sintática, cuja divisão em grupos entonacionais opera de acordo com um conjunto de condições de boa-formação.

Constitui propósito deste artigo observar que natureza subjaz à manifestação da Ênfase no que diz respeito ao relacionamento entre Fonologia e Sintaxe: (a) se associacionista ou dissociacionista; (b) se moderada ou radical; e, por fim, (c) se uni ou bilateral. Para atingir esse objetivo, passo, a seguir, à descrição do lugar da Prosódia na Teoria Fonológica atual, tomando por base o que chamo de abordagem (1) dissociacionista moderada unidirecional (Selkirk, 1984 e 1995) e (2) dissociacionista moderada bidirecional (Inkelas \& Zec, 1990 e 1995).

Selkirk (1984) vem a ser a principal representante do primeiro "casamento" acima apontado. Ela concebe um modelo de Gramática no qual o componente prosódico atua como mediador entre Sintaxe e Fonologia, postulando dois tipos de organização hierárquica nas representações fonológicas: (a) a estrutura prosódica de constituintes e (b) a estrutura rítmica. No primeiro tipo de organização, as unidades prosódicas (pé, palavra fonológica, frase entonacional etc.) aparecem progressivamente encaixadas em unidades maiores, formando parentetizações etiquetadas, de modo bastante parecido com a formalização adotada para a estrutura sintática. O segundo consiste numa hierarquia de níveis métricos que, representada por meio da grade, especifica periodicidades de ritmo recorrentes.

Dessa maneira, a representação fonológica de Selkirk integra (i) uma estrutura prosódica de constituintes; (ii) um conjunto de níveis autossegmentais; (iii) uma estrutura rítmica e, finalmente, (iv) a especificação de linhas de associação entre esses diferentes aspectos da representação. (Selkirk, 1984:33) O modelo de Gramática idealizado por Selkirk, no qual o componente prosódico figura na interface Fonologia-Sintaxe, aparece, na página 34 de seu texto, representado da seguinte maneira: 


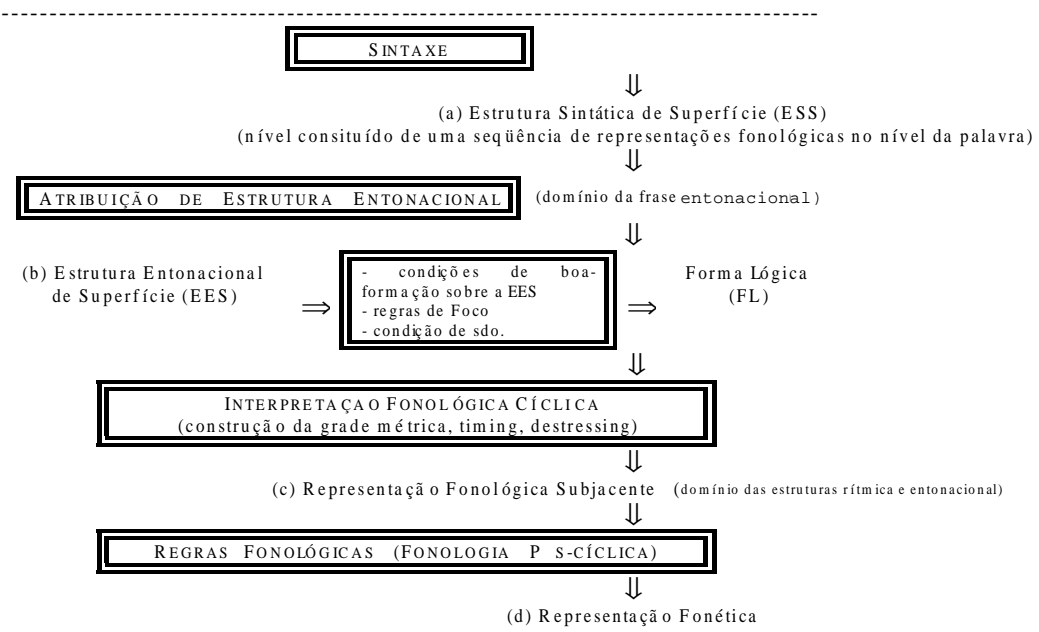

\section{Figura 1: Organização da Gramática na Visão de Selkirk (1984: 34)}

A abordagem de Selkirk (1984) tem a vantagem de integrar a Prosódia num modelo geral de Gramática. Pela figura 1, pode-se constatar que a estrutura prosódica constitui entidade distinta e independente da sintática, mas que com ela se relaciona por meio dos domínios hierárquicos, que se aplicam à saída do componente sintático. Dessa maneira, a Prosódia, nas palavras de Massini-Cagliari (1995: 102), é também lugar de aplicação das regras de mapeamento que transformam a estrutura sintática em uma estrutura prosódica hierarquizada, passível de ser submetida à aplicação das regras fonológicas pós-sintáticas (cf., também, Selkirk \& Shen, 1990; e Nespor \& Vogel, 1986 e 1989).

Com base na Figura (01), pode-se afirmar que o modelo de Selkirk (1984) é do tipo top-down (cf. Cagliari, 1994), haja vista que não prevê nenhum tipo de loop entre o nível da Estrutura Entonacional de Superfície (EES) e o da Estrutura Sintática de Superfície (ESS). Tal evidência justifica conceber a abordagem de Selkirk (1984 e 1995) como representativa de uma visão dissociacionista moderada unidirecional entre a Sintaxe e a Prosódia. Assim, no figura 02 a seguir, somente a primeira interferência é possível. 
Posição diferente da de Selkirk, assumem Inkelas \& Zec (1990) e Zec \& Inkelas (1995), que idealizam um modelo de Gramática no qual Sintaxe e Prosódia interagem bilateralmente. Com base em evidências sobre (i) colocação clítica e (ii) construções topicalizadas do servo-croata, os autores mostram que a Prosódia pode ter consequiências diretas na Sintaxe e, em função disso, argumentam que "abordagens que não permitam qualquer efeito da fonologia sobre a sintaxe são claramente inadequadas para descrever e interpretar dados conhecidos (...)". Por isso mesmo, concluem, "a influência da estrutura prosódica sobre a sintaxe pode ser expressa, num modelo não-derivacional, como fonte adicional de recursos para a construção das representações sintáticas, da mesma forma que o é a sintaxe para as representações fonológicas” (Inkelas \& Zec, 1990: 365-6).

O entendimento de Inkelas \& Zec (1990) a respeito da interface SintaxeFonologia aparece expresso na associação feita na figura 03. Vale ressaltar que no artigo de 1995, os autores rediscutem a questão, apresentando novas evidências que, acreditam (cf. p. 535), reforçam a proposta da mútua influência entre esses dois componentes.

$$
\text { Sintaxe }<<>>\text { Fonologia }
$$

Ao tratar da interface Sintaxe-Fonologia na Teoria da Optimalidade modelo de análise não-derivacional que prevê um conjunto de restrições hierarquizáveis — Goldston (no prelo) toma posição contrária à de Inkelas \& Zec (1990), argumentando em prol de um relacionamento unilateral entre os dois componentes. Para isso, propõe uma hierarquia gramatical, com base na qual afirma ser o material sintático alinhado acima do prosódico e este acima do morfológico, como na representação a seguir:

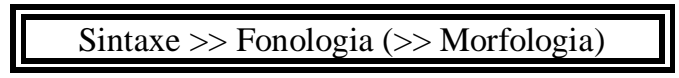

Após refletir sobre a conexão tomando por base dados do grego clássico, Goldston (no prelo) demonstra que a Prosódia é precedida pela Sintaxe, não podendo exercer influência direta sobre ela. Para a autora, a Fonologia apenas 
seleciona, como legítimo filtro, uma entre duas estruturas sintáticas disponíveis no enunciado. Em outros termos, a prosódia pode bloquear construções sintáticas somente quando há outras alternativas estruturais que apareçam no local das que foram bloqueadas (Goldston, no prelo: 27) 5 .

Como se vê, a polêmica Unilateralidade versus Bilateralidade ainda permanece. Trabalhos sobre a questão devem ser feitos, a fim de checar que perspectiva dá conta do fenômeno de interface estudado. Ao que tudo indica, a hipótese da Bilateralidade traduz melhor o fenômeno da Focalização, como pretendo demonstrar nas próximas seções. No entanto, o tema inspira reflexão e somente novas pesquisas poderão trazer luzes para o debate.

\section{Focalização: Sintaxe e Fonologia}

Uma das mais importantes funções que vêm sendo atribuídas à Prosódia nos últimos anos diz respeito à divisão dos enunciados em unidades informacionais, especialmente quando se trata do estabelecimento de relações de contraste no discurso (cf. Hirst \& Di Cristo, no prelo).

Cada unidade de contraste realiza-se dentro de um Grupo Entonacional definido, determinado aprioristicamente pelo falante, que pode reiterar, destacando, algo antes enunciado, não-entendido ou mal-interpretado por seu(s) interlocutor(es) (cf. Gonçalves, 1997). Dessa maneira, a Prosódia, independentemente ou em solidariedade com a Sintaxe, desempenha papel relevante tanto no modo como os falantes organizam quanto na maneira pela qual os ouvintes identificam a informação contrastiva envolvida no discurso oral dialogado.

A Entonação Contrastiva funciona, pois, como "Gatilho de Inferência Conversacional", uma vez que proporciona estabelecimento de confronto entre elementos do enunciado, cabendo à audiência a tarefa de recuperar, no fluxo da conversação, a relação de contraste que o falante intentou veicular. Nesse momento da interação, o ouvinte deixa aflorar seu conhecimento lingüístico, de mundo e partilhado (cf. Green, 1992) e estabelece uma relação não-explícita

${ }^{5} \mathrm{O}$ objetivo do texto de Goldston (no prelo) não é apenas descrever a situação de interface Fonologia-Sintaxe. Importa, para ela, que essa mesma relação tenha consequiências para uma hierarquia de restrições a fenômenos lingüísticos. Assim, uma pergunta para a qual a autora se propõe a dar resposta é a seguinte: a preferência pela não-ocorrência de determinada forma lingüística, em certo contexto, obedece a restrições de nível sintático ou prosódico? 
entre dois elementos do texto conversacional que busca compreender e interpretar, construindo, assim, sua coerência.

A proeminência acentual, nos casos (01) a (03) abaixo, rege as relações de sentido expressas na sentença, desencadeando, dessa forma, inferências as mais diversas. $\mathrm{O}$ enunciado (01), por exemplo, pronunciado com Acento Enfático $^{6}$ no SN 'a prima da Marcelina', particulariza o sujeito da oração e autoriza deduzir que o falante teve o propósito de dizer que foi mesmo a prima da Marcelina (e não outra pessoa qualquer, como a Josefina ou a Dagmar) a intérprete em questão. O mesmo raciocínio se aplica a (02), no qual a saliência prosódica no SP ‘do João Bosco’ permite que se conclua ter sido gravado pela prima da Marcelina um samba desse compositor (e não de outro, como o Gonzaguinha ou o Chico Buarque).

(01) A PRIMA DA MARCELINA gravou um samba do João Bosco. (e não a Cândida, a Filomena ou a Francisca)

(02) A prima da Marcelina gravou um samba DO JOÃO BOSCO. (e não do Caetano Velloso ou do Gilberto Gil)

(03) A prima da Marcelina gravou um SAMBA (do João Bosco). (e não outro gênero musical, como o bolero, a valsa ou jazz)

Pelos exemplos, pode-se concluir que a Entonação participa diretamente da expressão do conteúdo de um enunciado, em nível de importância semelhante ao das unidades sintáticas e morfolexicais. Várias evidências podem ser depreendidas a partir do que foi exposto: (1) os enunciados contêm um terceiro nível de organização (a Prosódia), ao lado da Sintaxe e da Semântica; (2) os principais expoentes desse módulo da Gramática são, entre outros, o Acento, a Entonação e o Ritmo; (3) a interpretação semântica de um enunciado depende tanto de sua configuração sintática quanto da Entonação a ela conferida, haja vista que (3b) uma mesma seqüência linear de elementos pode ter o sentido levemente modificado (nuançado) pela atribuição de proeminência prosódica a um de seus constituintes; (4) a Focalização, na qualidade de categoria discursivo-pragmática que expressa contraste (cf. Gonçalves, 1997), pode ser

${ }^{6}$ A proeminência fonológica requerida pela Entonação Contrastiva pode ser acolhida sob o rótulo genérico de 'Acento Enfático', considerado, aqui, como "gatilho de Focalização Prosódica". Não considero problemático o uso do termo, uma vez que o elemento focalizado apresenta-se modificado em sua configuração prosódica tida como "normal" ou "básica": uma de suas sílabas sobressai significativamente sobre as demais, criando uma alternância rítmica mais intensa entre batimentos fortes e fracos. Como o acento é definido atualmente como uma relação de proeminência (cf. Libermann \& Prince, 1977), parece-me adequado o uso da expressão. 
veiculada por expedientes de natureza suprassegmental, unicamente. Dessa maneira, (5) a Sintaxe não é o principal veículo de exteriorização/manifestação desse fenômeno, uma vez que (5b) tal categoria pode não requerer qualquer alteração de natureza sintática (nos exemplos, nenhum tipo de transformação — clivagem, deslocamentos — aparece associada à identificação do elemento focalizado). Por essa razão, (6) há necessidade de conceber um módulo prosódico independente do sintático, haja vista que a Fonologia mantém sua independência em relação à Sintaxe, isto é, deve-se prever algum tipo de dissociação entre esses dois componentes.

Da mesma forma que o italiano, o grego, o inglês e a maior parte das línguas do mundo (cf. Hirst \& Di Cristo, no prelo), o português do Brasil utiliza tanto meios textuais (morfológicos, lexicais e sintáticos) quanto prosódicos (Acento Enfático) para focalizar contrastivamente um elemento do texto. Em nossa língua, no entanto, o meio textual nem sempre basta para garantir a indicação do contraste. Dessa maneira, o casamento Sintaxe-Fonologia, nesse caso especificamente, não é de todo monogâmico, uma vez que contrastes nem sempre são manifestos com atuação simultânea desses domínios da Gramática. De fato, determinadas estratégias sintáticas, como as orações cindidas e a topicalização, podem expressar informação contrastiva. No entanto, pretendo comprovar, neste artigo, que o Acento Enfático é, no português do Brasil (doravante PB), o verdadeiro atribuidor da significação contrastiva veiculada nessas construções.

Duas foram as evidências que me autorizaram concluir em favor da predominância da 'Focalização Prosódica' sobre a 'Textual'7 , cabendo à Sintaxe, e não à Fonologia, como acreditam, entre outros, Jackendoff (1972) e Freitas (1995), o caráter redundante/acessório:

(1) há enunciados que veiculam contraste, muito embora não sejam marcados pela presença de qualquer elemento formal (conjunção adversativa, partículas negativas) que possa atribuir significado contrastivo ao item enfatizado e

(2) constituintes topicalizados e sentenças clivadas, principais estratégias textuais de Focalização, podem não veicular informação contrastiva.

\footnotetext{
${ }^{7}$ Chamo de 'Focalização Textual' as estratégias morfossintático-lexicais resposáveis pela atribuição de Ênfase Contrastiva (cf., entre outros, a clivagem, a topicalização, o uso de advérbios focalizadores e o emprego de quantificadores).
} 
Em texto de 1981, Prince já observara que, no inglês, o contraste não constitui efeito necessário à topicalização de constituintes (mesma constatação feita por Taglicht, 1984: 119). No que diz respeito ao PB, estou bastante convencido de que o contraste também não é essencial em sentenças com deslocamentos para a posição de SN inicial e externo, sejam eles casos típicos de topicalização (TOP) ou de deslocamento à esquerda (DE). Os exemplos de (04) proporcionam confirmar essa hipótese. Observe-se, entretanto, que eles podem transformar-se em contrastivos, mediante a Entonação que lhes seja conferida. Isso constitui evidência de que o Acento Enfático é, no PB, o verdadeiro elemento atribuidor da significação contrastiva, cabendo ao deslocamento para o início da sentença, isto é, à construção sintática, o caráter de redundante. Confira-se, então, a contraparte enfática de (04), logo a seguir, nos exemplos prototípicos de $(05)^{8}$.

(04) a. Esse computador, eu comprei quando (es)tava trabalhando lá na Companhia. (PAU [20], 19 a., 2o. grau)

b. A Abigail, não se pode confiar nela não que ela já amostrou pra gente que é fofoqueira. (JAQ [63], 10 a., primário)

(05) a. ESSE COMPUTADOR, eu comprei quando (es)tava trabalhando lá na Companhia. (não comprei essa máquina de escrever elétrica, por exemplo)

b. A ABIGAIL, não se pode confiar nela não porque ela já amostrou p(a)ra gente que é muito fofoqueira. (mas a Celeste ou a Madalena não, porque são sinceras)

Callou et alii (1993), investigando a relação Sintaxe-Prosódia nas construções topicalizadas/deslocadas à esquerda, também notaram não ser TOP/DE a principal construção para marcar Foco (ou 'Ênfase Contrastiva', como usado neste artigo — cf. nota de número 1) na língua portuguesa. Por essa razão lançaram, na página 356, a suspeita de que devem os falantes cultos preferir para isso outras variantes, como, por exemplo, as construções clivadas do tipo Foi SN que SV. De fato, o Acento Enfático de contraste é, em termos percentuais, bem mais freqüente em construções clivadas que em casos de TOP/DE. Se, por um lado, o Acento Enfático se faz mais autuante quando o enunciado apresenta uma clivada, por outro, nem toda oração cindida veicula contraste. Em outras palavras, o uso de uma relativa-equacionada (cf. Taglicht, 1984), por si só, não permite conferir significado contrastivo ao texto. O exemplo

\footnotetext{
${ }^{8}$ Nestes e em outros exemplos, utilizo caixa alta, negrito e itálico para indicar que o termo foi realçado prosodicamente através do Acento Enfático. O sublinhado indica que o elemento foi focalizado apenas do ponto-de-vista textual (morfossintático).
} 
(06) revela um caso de cleft-sentence que não favorece, sem auxílio dos elementos prosódicos, uma leitura contrastiva.

(06) Já teve três desfiles esse ano aqui, mas eu não quis desfilar porque eu não tenho muito jeito não .... A minha irmã desfilou ... Inclusive foi a colega dela que organizou o desfile. (GUS [62], 10a., ginásio).

Não há, em qualquer dos casos de 'Focalização Textual' (topicalização, comparação, clivagem, repetição — cf. nota 6), sobreposição categórica com o Acento Enfático. Mesmo as orações cindidas, que despontaram como principal expediente sintático para emergência de proeminência prosódica, sozinhas não conseguem assegurar o contraste. Conforme também observou Braga (1991: 113), a configuração estrutural dos constituintes, no caso das clivadas e das pseudoclivadas, é critério necessário, mas não suficiente, à veiculação do contraste. Nas palavras da autora, nos enunciados que contêm orações cindidas é a presença do auxiliar ser elou do pronome relativo, a envolver total ou parcialmente o constituinte, conjugada ao padrão entonacional que levam à sua focalização, simultaneamente autorizando, em enorme número de casos, uma leitura contrastiva da SC (= sentença clivada).

Em decorrência do que se expôs, proponho ser a 'Focalização Prosódica', no $\mathrm{PB}$, a principal estratégia utilizada para contrastar elementos do texto. Por essa razão, defendo ser o Acento Enfático o atribuidor de contraste stricto sensu em nossa língua. Dito de outra maneira, a Prosódia, pelo menos no PB, não constitui traço acessório (redundante) na veiculação do contraste, conforme sugerido em Chomsky (1971), Jackendoff (1972) e Guimarães (1978), entre outros. Horvath (1986: 116), por exemplo, acredita que o Foco é o constituinte do enunciado primeiramente identificado por transformações sintáticas e, somente a posteriori, sobremarcado pela Entonação. Para esses autores, o Foco de contraste é fenômeno sintático que, sob certas circunstâncias e/ou restrições, pode vir reforçado pela Prosódia (cf. Jackendoff, 1972).

Também discordo de Freitas (1995: 162-3), que, ao estabelecer um exaustivo levantamento dos suprassegmentos incidentes na fronteira de constituintes, chega à seguinte afirmação: o foco vem a ser uma categoria sintaticamente motivada, ou seja, operações sintáticas de deslocamento que alteram a ordem canônica do enunciado já constituem, por si mesmas, recursos que tornam salientes determinados constituintes. Mais adiante, conclui: a prosódia tende a sobremarcar essa saliência,atribuindo proeminência a esses constituintes, inclusive mediante foco restrito. 
Ao contrário do que propagam Horvath (1986) e Freitas (1995), pude constatar que, no PB, é a informação sintática quem necessita de reforço acentual - e não o contrário. Aqui, a redundância parte da Sintaxe e não da Prosódia, portanto. Nesse sentido, o fenômeno da Focalização reforça a proposta de um módulo prosódico autônomo, independente do sintático, uma vez que o Acento Enfático prescinde de transformações sintáticas, muito embora possa ser veiculado paralelamente a determinadas estruturas (clivagem e deslocamentos, por exemplo). Isso, no entanto, não constitui condição sine qua non para a manifestação do Foco de contraste, como imaginaram, entre outros, Chomsky (1971), Jackendoff (1972), Horvath (1986) e Freitas (1995).

Pode-se admitir, portanto, que o relacionamento entre Sintaxe e Fonologia jamais poderia ser do tipo 'dissociacionista radical', haja vista não serem negados os vínculos naturais entre os dois módulos. Além disso, aproveitando as palavras de Bolinger (1989: 106-7), a Sintaxe, no caso do contraste, não é independente da Entonação, que se junta a ela posteriormente.

Também não faz sentido propugnar uma aliança de caráter meramente 'associacionista' para acolher a conexão entre Sintaxe-Prosódia no PB. No caso da Ênfase Contrastiva, especificamente, esses níveis de descrição almejam um "relacionamento com maiores liberdades", isto é, sem "muita dependência de uma das partes". De fato, no caso do fenômeno investigado, não me parece adequado propor um componente prosódico gerado a partir do sintático, prevendo correspondência sistemática entre eles, haja vista que a Prosódia mantém sua individualidade, não sendo traço redundante a acompanhar a configuração sintática.

Por eliminação, defendo a necessidade de instituir interface do tipo 'dissociacionista moderada' entre os componentes sintático e fonológico da língua. Nesse sentido, as evidências me levaram a considerar que os dois níveis organizam o mesmo material de modo autônomo, muito embora não se rejeite a idéia de os constituintes coincidirem nos dois planos. Resta saber, ainda, se se trata de um relacionamento (a) uni ou (b) bidirecional, questão a ser discutida na próxima seção.

\section{Parâmetros da Focalização}

Admitindo-se que a Focalização é categoria existente na Gramática Universal, pode-se dizer que esse fenômeno ocasiona variações paramétricas, visto que sua materialização pode ocorrer sob formas variadas, em diferentes sistemas lingüísticos. Estabelecem-se as seguintes possibilidades de 
exteriorização do fenômeno nas línguas do mundo, de acordo com Gonçalves (1997):

(1) o elemento responsável pela Focalização pode ser (a) um morfema lexical livre (palavra, propriamente) ou (b) uma partícula presa agregada a bases, antes ou depois, para imprimir contraste e/ou intensificação;

(2) a Focalização pode ser impressa por uma categoria sintática nãolexical, com posição definida na estrutura da frase, como, por exemplo, o deslocamento para o início ou para o final do enunciado;

(3) oflash de um termo pode ser assinalado por meio de um traço sintático atribuído, em condições estruturais definidas, por uma categoria (lexical ou funcional) a outra, de forma semelhante à que ocorre com $\mathrm{V}$ (verbo) e com I (flexão); e, finalmente,

(4) a Focalização pode dar por um traço fonológico associado a um dado constituinte em domínios prosódicos específicos, como, por exemplo, o Sintagma Fonológico (j) ou a Frase Entonacional (I) (cf. Nespor \& Vogel, 1986 e 1989).

O PB faz uso das quatro estratégias apontadas, uma vez que a Focalização pode ser veiculada por um morfema, como acontece com os afixos de grauestratégia (1). Além disso, pode ser determinada por uma categoria sintática não-lexical (ordem dos constituintes) — recurso (2) — , visto que a topicalização de termos freqüentemente leva à sua Ênfase no texto. Adicionalmente a essas duas estratégias, a língua portuguesa tende a focalizar um vocábulo por meio de outro, especialmente nos casos que denominei de 'Ênfase Intensiva com Marcador Focal' (cf. Gonçalves, 1997), nos quais um advérbio ou um quantificador funcionam como autênticos "Morfemas de Ênfase" — recurso (3). Finalmente, a Focalização pode vir impressa apenas pelo uso da Fonologia, associado a um termo num domínio prosódico específico. A chamada 'Ênfase Intensiva sem Marcador Focal' (cf. Gonçalves, 1997: cap. 4) não requer quantificadores $^{9}$ para carrear a noção de intensidade, o que mostra ser o Português uma língua que também atualiza a estratégia (4). Os exemplos (07)(10) ilustram, na ordem acima apresentada, as várias possibilidades de materialização do fenômeno no PB:

(07) A casa nova do Venceslau ficou muito boa. Eu realmente achei a sala CHIQUÉRRIMA. O quarto ficou ULTRA-SOFISTICADO. E a cozinha...

\footnotetext{
${ }^{9}$ Estou entendendo que valores semânticos associados a aspectos verbais, iteração e intensidade constituem uma espécie de quantificação (a quantificação adverbial). A esse propósito, ver Partée (1995: 546-8).
} 
Adorei de montão. (Exemplo constante do Corpus de ControleGonçalves, 1997: 385)

(08) Eu trabalhei um ano e meio... um ano e meio como entregador... que eu tinha uma Kombi...eu era motorista autônomo. E ESSA KOMBI, eu engajei nessa mesma firma que é do meu tio. (MAN [14], 30a.,primário)

(09) Todos os domingos a Dona Dalva aprimora seus dotes culinários. Supergostoso o nhoque de aipim que ela faz. E o pavê de frango? APETITOSO PACAS ele é. Com aquelas batatinhas, então, nem se fala. Huuum! (Exemplo constante do Corpus de ControleGonçalves, 1997: 285)

(10) A Andréa cozinha bem de herança... ela aprendeu com a mãe, que é uma excelente cozinheira. E por falar nisso, a Dona Dalva fez ontem uma carne assada GOSTOOOOOSA! (Exemplo constante do Corpus de Controle—Gonçalves, 1997: 291)

Para dar conta das variações da Focalização, proponho que o fenômeno seja acolhido por meio do traço [+/- sintático $]^{10}$. Dito de outra maneira, sugiro que essa categoria, presente em todas as línguas na qualidade de fenômeno discursivo-pragmático, pode vir expressa pela Sintaxe, predominantemente, ou não. Nesses termos, minha abordagem difere da de Horvath (1986), uma vez que, no meu entender, a Focalização é fenômeno discursivo-pragmático. Sua exteriorização é que, em algumas línguas, como o Húngaro, por exemplo, pode ser de natureza sintática. Portanto, a manifestação pela Sintaxe é vista, aqui, apenas como parâmetro que as línguas selecionam.

Uma língua de Focalização [+ sintática] faz uso de expedientes como clivagens e deslocamentos para carrear contraste e/ou intensificação, semânticas predominantes da Focalização de termos. A Prosódia, nesse caso, pode participar — mas não necessariamente — como reforço a essa marcação prévia, num enlace que pode ser denominado de 'associacionista', já que o nível suprassegmental irá constituir informação redundante, sempre acompanhando a configuração sintática do enunciado.

Nos casos em que o Focalização é do tipo [- sintático], proponho o uso

${ }^{10}$ A escolha do traço [+/- sintático] — e não do [+/- fonológico] — como o primeiro a determinar variações paramétricas nas línguas se justifica no sentido de ser senso-cumum na Teoria Fonológica (cf., p. ex., Selkirk, 1984 e 1995; Nespor \& Vogel, 1986 e 1989; Selkirk \& Shen, 1990; e Vogel \& Kenesei, 1990) a idéia de que a Sintaxe precede derivacionalmente a Prosódia. 
do traço [+/- fonológico] para dar conta da distinção entre (1) línguas nas quais a Ênfase vem expressa pela Morfologia, unicamente, através da aposição de morfemas específicos para contraste e para intensificação (cf., p. ex., o árabe e o marubo) e (2) línguas em que os meios prosódicos são os relevantes à emergência da Ênfase (cf., p. ex., o PB e o espanhol). Às primeiras, atribuo a especificação [- sintática; - fonológica], ao contrário das últimas, rotuladas de [- sintática; + fonológica].

Uma língua com Focalização [+ fonológica] tem a capacidade de pôr um elemento do texto em destaque usando tão-somente meios prosódicos. Com isso, estou querendo argumentar que a Prosódia pode prescindir de marcas textuais (morfemas, palavras e construções sintáticas) para veicular a informação focal: o Acento Enfático é, nessas línguas, auto-suficiente para asseverar as semânticas da Focalização. Nesses casos, a conexão SintaxeFonologia tende a ser do tipo 'dissociacionista moderada', uma vez que a Prosódia é independente da Sintaxe, mas pode entrar em comunhão com ela, em maior ou em menor proporção.

Partindo do pressuposto de que a Sintaxe precede derivacionamente a Prosódia (cf., p. ex., Selkirk, 1984 e 1995; e Nespor \& Vogel, 1986 e 1989 e nota 9), poder-se-ia pensar num Quadro, como (01) abaixo, para sintetizar minha proposta de parametrização da categoria 'Focalização'. Observe-se que (01) subordina o traço [+/- fonológico] ao [+/- sintático], sem prever qualquer espécie de loop: é um esquema do tipo top-down. Por meio dessa representação, depreendem-se três possibilidades combinatórias: (a) [+ sintático]; (b) [sintático; - fonológico] e (c) [- sintático; + fonológico].

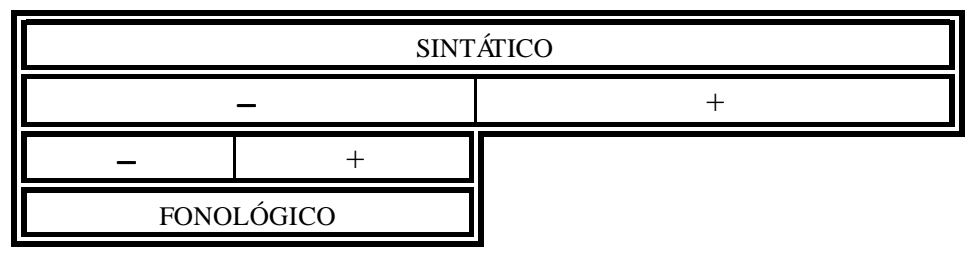

\section{Quadro 1: Parâmetros da Focalização: tentativa de caracterização.}

Como se vê, o Quadro (01) é problemático por excluir a combinação [+ sintático; + fonológico] do inventário das possibilidades de materialização ${ }^{11}$. Inverter a posição dos parâmetros não me parece a solução mais adequada, pois essa mudança (a) faria pressupor que a Fonologia, além de preceder derivacionalmente a Sintaxe, tem efeitos diretos sobre ela, sendo fonte básica 
de recursos para a construção das representações sintáticas; e (b) não eliminaria o problema inicial, pois, ainda, assim, o Quadro (01) não iria prever a combinação [+ fonológico; + sintático].

Nas línguas que selecionam o valor positivo do traço [+/- sintático], a Prosódia pode atuar como expediente extra na atribuição do contraste e/ou da intensificação, constituindo, portanto, informação redundante àquela já expressa textualmente (cf. kutenai e húngaro, p. ex). Nas línguas de Focalização [+ fonológica], como o PB, a fonologia, apesar de ser o principal recurso usado para destacarar um elemento do texto, pode operar em conjunto com determinadas estratégia sintáticas e, nesse caso, é a sintaxe quem constitui informação extra.

Como se pode perceber, a escolha do valor positivo de um dos traços propostos não descarta, necessariamente, a marcação positiva do outro. Ao contrário, os parâmetros da Focalização não são mutuamente excludentes e, por isso, a combinação $[+;+]$, seja qual for a ordem adotada, é de fato produtiva. No entanto, o valor positivo do primeiro tende a implicar redundância do segundo, haja vista que um deles sempre sobressai, nas línguas, como principal expediente para a materialização do fenômeno. Em decorrência disso, a solução mais viável seria conceber os parâmetros da Focalização independentemente, sem subordinar um ao outro, mas prevendo certo grau de interação eles. A Figura (02) a seguir tem o propósito de traduzir esse tipo de relacionamento.

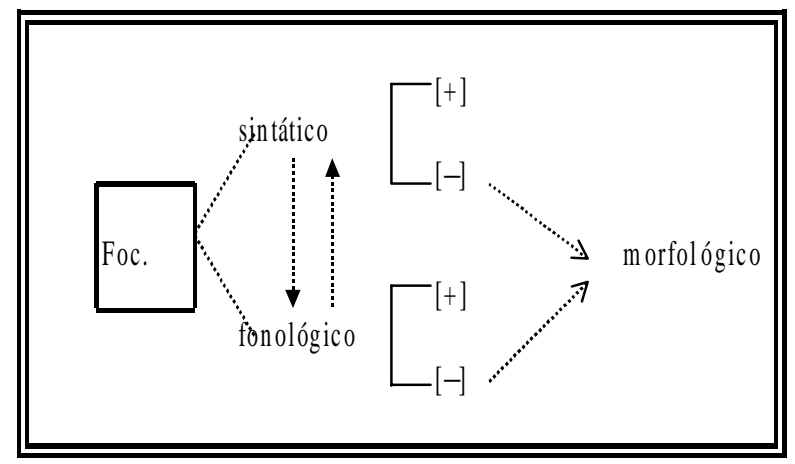

Figura 2: Reanálise dos parâmetros da Focalização.

${ }^{11}$ Outra solução seria questionar se essa possibilidade de fato existe nas línguas e ignorar a combinação. Acredito não ser essa a alternativa mais acertada, haja vista que a maior parte das línguas manifesta Focalização com atuação concomitante de expedientes sintáticos e prosódicos (cf. seção 4). 
Em (02), os parâmetros [sintático] e [fonológico] constituem alternativas de que as línguas dispõem para manifestar a categoria 'Focalização'. Assim, quando o valor positivo do primeiro parâmetro é selecionado, os meios sintáticos, por si sós, bastam para destacar um elemento do texto. Como os parâmetros se interrelacionam bilateralmente, nada impede que uma língua de Foco [+ sintático] faça uso também de expedientes prosódicos. Nesse caso, a informação fonológica será redundante em relação à sintática.

Quando uma língua seleciona o valor positivo do segundo parâmetro, a Prosódia não necessita de qualquer informação sintática: o nível suprassegmental é auto-suficiente para enfatizar o item desejado. Devido à bidirecionalidade, também é possível que uma língua de Foco [+ fonológico] empregue estratégias sintáticas, paralelamente ao chamado Acento Enfático. Aqui, no entanto, a informação sintática é que será redundante.

Por fim, no caso de uma língua não selecionar o valor positivo de nenhum dos parâmetros, a Focalização vem manifesta pela Morfologia, ou seja, um 'Morfema de Enfase' será o elemento responsável pela iluminação do elemento destacado no texto. O árabe e o marubo exemplificam línguas de especificação [- sintática; - fonológica]. Cumpre destacar que 'morfológico' não é propriamente um traço, resultando, antes, da combinação de valores negativos dos parâmetros propostos ${ }^{12}$.

A proposta de interface que subjaz à Figura (02) é, como se pode notar, do tipo 'dissociacionista moderada bidirecional'. De fato, um enfoque 'associacionista' não condiz com a verdadeira natureza da manifestação da Focalização nas línguas do mundo, tendo em vista que (a) não há uma correspondência sistemática entre os dois módulos e (b) a Prosódia nem sempre opera como marcação redundante em relação à Sintaxe. Uma abordagem 'dissociacionista radical' também não dá conta do relacionamento em questão, haja vista que os componentes fonológico e sintático têm, no que diz respeito à exteriorização do fenômeno, enorme "vocação ao casamento", em decorrência de muitas vezes atuarem em solidariedade para destacar um elemento do texto.

${ }^{12}$ Nada impede, no entanto, que a Fonologia venha a realçar os elementos morfológicos responsáveis pela Focalização nessas línguas. Ao que tudo indica, o árabe tende a reforçar, através da Prosódia, o 'Morfema de Ênfase'. No entanto, a elevação na altura, de caráter não-obrigatório, pode estar vinculada, mais restritivamente, a fatores como (a) grau de informatividade/relevância do contraste, (b) modalidade da sentença, e (c) atitude do falante. 
Como se vê, o enfoque 'dissociacionista bilateral' é o que melhor traduz a interface Sintaxe-Fonologia na emergência da Focalização, uma vez que (1) a Prosódia mantém sua independência em relação à Sintaxe nas línguas em que a Entonação, por si só, coloca um elemento em evidência no texto; (2) o principal veículo de exteriorização do fenômeno será, nas línguas do mundo, ou a Sintaxe ou a Fonologia. Em outras palavras, se, por um lado, há línguas em que os meios sintáticos são os que bastam para destacar um elemento do texto, por outro, também há línguas em que os meios prosódicos são os relevantes. A evidência (2) permite que se conclua ser um modelo não-derivacional o mais adequado para explicitar o relacionamento entre os dois parâmetros em discussão. Nesse sentido, a abordagem de Inkelas \& Zec (1990) e de Zec \& Inkelas (1995), na qual Sintaxe e Prosódia interagem bidirecionalmente, é a que melhor condiz com os fatos observados na manifestação da categoria analisada neste artigo.

\section{Pequeno estudo de caso(s)}

Nesta seção, pretendo mostrar como a Focalização se manifesta em alguns sistemas lingüísticos, a fim de argumentar que os parâmetros propostos na seção 3 realmente captam o comportamento do fenômeno em línguas de famílias as mais diversas. Para tanto, informações esparsas em compêndios e/ou artigos, entrevistas com amigos-lingüistas e conversas com falantes nativos constituirão minha fonte de análise nesta parte do trabalho.

Em marubo ${ }^{13}$, uma língua indígena brasileira da família Pano, o Focalização vem expressa pelo morfes $\{-\mathrm{Ro}\}$ e $\{-\mathrm{kW}\}$ que, agregados a bases verbais e nominais, respectivamente, imprimem significado contrastivo ao elemento ao qual se anexam. O acréscimo desse formativo não acarreta qualquer modificação nos padrões entonacionais, como se constatou em Costa (1992), o que faz com que essa língua seja especificada como do tipo [- fonológica; - sintática].

Da mesma forma que o marubo, o árabe ${ }^{14}$ também é exemplo de língua com Foco [- sintático; - fonológico]. Nesse caso, o segmento enfatizado sempre vem seguido pelo morfe $\{-1 \mathrm{i}\}$, sem qualquer alteração na melodia da fala. Nesse idioma, é possível associar um tom alto à partícula que detém o sentido contrastivo. No entanto, a elevação na altura, de caráter opcional, pode estar vinculada, mais diretamente, a fatores como (1) grau de informatividade/ relevância do contraste (isto é, à importância da correção); (2) modalidade da

${ }^{13}$ Agradeço à amiga Raquel Romankevicius Costa tanto pelas informações sobre o marubo quanto pelas sugestões e críticas ao trabalho. 
sentença (ao que parece, é mais freqüente em perguntas que em asserções); e (3) volume da voz, especialmente nos casos em que carreia atitude do falante, como ironia, por exemplo. Por esses motivos, o tom alto vinculado à partícula $\{-$-li $\}$ se explica mais pelas funções indexical e atitudinal imputadas à Prosódia (cf. Gonçalves, no prelo) que em decorrência do conteúdo semântico expresso pela Ênfase, propriamente.

No húngaro, o Acento e a Entonação não são suficientes, por eles mesmos, para fazer de um constituinte o item focalizado. O mesmo acontece em Kutenai, uma língua indígena norte-americana ${ }^{15}$. No primeiro caso, apesar de freqüentemente haver elevação na altura do termo/expressão focalizado, a Prosódia vem a constituir informação que "escolta" a configuração sintática do enunciado, já que o contraste se associa, via de regra, (1) à topicalização de constituintes, no caso de complementos enfatizados, e (2) à clivagem de termos, no caso de adjuntos enfatizados. No segundo caso, a Focalização também é sintaticamente motivada, visto (a) ser o Foco levado, categoricamente, para o final da sentença ('Foco Final') e (b) a Prosódia tender, na verdade, a sobremarcar essa saliência estrutural, atribuindo proeminência a esse mesmo constituinte.

Nos dois casos, a Entonação apresenta correspondência direta para com o plano sintático-estrutural. De fato, é a estrutura sintática que irá determinar os padrões melódicos e não vice-versa. Dito de outra forma, os padrões prosódicos, em húngaro e kutenai, seriam redundantes, visto que ocasionados por uma estrutura sintática. Nesse sentido, a Focalização é, nos dois casos, do tipo [+ sintático; + fonológico], em decorrência de (1) a Fonologia não constituir condição primeira ao realce de termos por contraste e/ou por intensificação e (2) a informação sintática (e não a morfológica, como em árabe e marubo) ser relevante à emergência da Ênfase.

Como o português, o inglês também pode ser tomado como caso ilustrativo de língua com Focalização [+ fonológica]. Embora sentenças relativoequacionadas (ou clivadas) freqüentemente acompanhem os contrastes, elas não constituem condição única para sua emergência, pois, como evidencia Taglicht (1984: 19-20), a elevação na altura pode, sozinha, colocar um termo em Foco. De fato, um enunciado como (11) não apresenta qualquer informação textual e, apesar disso, expressa contraste, pondo o SN 'the shed' em evidência no discurso.

${ }^{14}$ Agradeço a Suleima Abdul Ali, falante-nativo, pelas informações sobre essa língua.

${ }^{15}$ Informações obtidas a partir de Horvath (1986). 
(11) John painted THE SHED yesterday. (not the door)

'John pintou $O$ TELHEIRO ontem'. (não a porta)

Também o espanhol é uma língua de Focalização [+ fonológica], haja vista que a Entonação, embora freqüentemente vinculada ao "crivo" (cf. Hirst $\&$ Di Cristo, no prelo: 45), como em (12), pode ser soberana na tarefa de destacar contrastivamente um elemento expresso no conversa (cf. (13)). Como em nossa língua, as cleft-sentences, sem o auxílio do Acento Enfático, não são capazes de expressar contraste também em espanhol, como se verifica em (14).

(12) PEDRO fue quien me enteró de la noticia. (... y no José)

'Foi PEDRo que me pôs a par das novidades' (e não José)

(13) He leído EL LIBRo que me prestaste. (... no el articulo)

'Li o LIVRo que você me emprestou' (não o artigo)

(14) Fue el libro que me prestaste. (= esto es el libro que me prestaste)

'Foi o livro que você me emprestou' (= este foi o livro que me você emprestou)

\section{O Foco Final lusitano}

No que diz respeito à exteriorização do Foco de contraste, há uma pequena diferença entre as variantes brasileira e européia da língua portuguesa. Nesta última, conforme aponta Martins (1992: 187), há forte pressão para que a expressão enfatizada seja posta no final do Grupo Entonacional, em especial nos casos de correção. Esse deslocamento vem recebendo o rótulo de 'Foco Final', nos termos de Martins (1992:189); Frota (1994: 6); e Hirst \& Di Cristo (no prelo: 46), entre outros.

O português do Brasil de fato tende a não movimentar o elemento focalizado para o final da sentença, sendo, antes, bem mais freqüente (i) sua topicalização ou (b) sua clivagem, como vimos. O português europeu (doravante PE), ao contrário, apresenta o Foco deslocado para o final da sentença em cerca de $80 \%$ dos casos, de acordo com os resultados apresentados por Martins (1992). Observem-se os exemplos:

(15) A. Você prefere que ela vá embora, não é?

B. Não. Eu prefiro que ela VENHA.

(16) A. Você prefere que ela venha, não é?

B. Não. Eu prefiro que venha ELE. 
Na conclusão do trabalho, Martins (1992: 194) afirma que há limites para a liberdade na ordem dos constituintes e os recursos entonacionais tomam lugar, nos casos em que restrições gramaticais proíbem o deslocamento de uma palavras contrastada para a posição final. Além disso, a autora observa que o recuo para o fim da sentença, mesmo nos casos sem "restrições gramaticais", não é obrigatório, haja vista que muitos contrastes não implicam quaisquer deslocamentos (p. 195) e, em decorrência disso, o Foco Final não constitui, em PE, um princípio.

Martins (1992) evidencia que muitos casos de Focalização de forma alguma necessitam de informações sintáticas, devendo, por isso, ser atribuídos à Entonação alta e ascendente, que sempre atua na identificação do Foco (p. 196). Nesse sentido, o PE, da mesma forma que o PB, vem a se especificar, quanto à manifestação do fenômeno, como língua do tipo [+ fonológica], em decorrência de os recursos sintáticos terem papel relevante, mas não constituírem condição preponderante para destacar um termo.

\section{Conclusão}

Pelo que se expôs no decorrer do artigo, pode-se admitir que a proposta de interface que melhor condiz com os fatos observados na Focalização é a 'dissociacionista moderada bidirecional' (cf. seção 1). Cumpre ressaltar, no entanto, que não estou dando qualquer veredicto acerca da polêmica Unilateralidade versus Bilateralidade na conexão Sintaxe-Fonologia. Estou afirmando, apenas, que essa proposta permite captar melhor o relacionamento em questão no fenômeno estudado. Como ressaltei mais acima, o tema inspira reflexão e somente novas pesquisas na área poderão lançar novas luzes sobre esse debate.

(Recebido em julho de 1998. Aprovado em julho de 1999)

REFERÊNCIAS BIBLIOGRÁFICAS

Abaurre, M. B. M. (1996) Acento frasal e processos fonológicos segmentais. Letras de Hoje. Porto Alegre: PUC/RS, 31 (2): 41-50.

Bolinger, D. (1989) Intonation and its uses. London: Edward Arnold.

Braga, M. L. (1991) As sentenças clivadas no Português falado no Rio de Janeiro. Organon. Porto Alegre: UFRGS/Instituo de Letras, 19 (1): 10925.

CAGliari, L. C. (1994) Regras de feedback. Fonologias: análises não-lineares. Letras de Hoje, Porto Alegre, 29 (4): 55-76. 
CAllou, D. et alii (1993) Topicalização e deslocamento à esquerda: sintaxe \& prosódia. In: Castilho, Ataliba (org.). Gramática do Português falado: as abordagens. Campinas: Ed. da UNICAMP/FAPESP, vol.3, p. 315-61. Callou, D.; Moraes, J. A. de; \& Leite, Y. de F. (1993) A topicalização no Português do Brasil: sintaxe \& prosódia. Anais do II Congresso da ASSELRIO. Rio de Janeiro: UFRJ/ASSEL-RIO, p. 89-97.

Chomsky, N. (1971) Deep structure, surface structure and semantic interpretation. In: SteInBERD, D. \& JACOBOvits, L. (orgs.) Semantics: an interdisciplinary reader in Philosophy; Linguistics and Psycology. Cambridge: Cambridge University Press, p. 183-216.

Costa, R. G. (1992) Padrões rítmicos e marcação de caso em Marubo. Dissertação de Mestrado em Lingüística. Rio de Janeiro: UFRJ/Faculdade de Letras, mimeo.

Freitas, M. A. de (1995) Prosódia \& sintaxe: delimitação e contraste de estruturas. Tese de Doutorado em Lingüística. Rio de Janeiro: UFRJ/ Faculdade de Letras, 228 p., mimeo.

Frota, Sónia (1994) Aspectos da prosódia do Foco no português europeu. Fonologias: análises não-lineares. Letras de Hoje, Porto Alegre, 29 (4): $77-100$.

Goldston. C. (no prelo). The syntax-prosody interface in Optimality Theory. A sair.

Gonçalves, C. A. V. (1997) Focalização no Português do Brasil. Tese de Doutorado em Lingüística. Rio de Janeiro: UFRJ/Faculdade de Letras, 401 p., mimeo.

Gonçalves, C. A. V. (no prelo) Os limites movediços da Prosódia. Expressão. Teresina: UFPI, inédito.

GreEn, G. (1992) Pragmatics and natural language understanding. Hillsdale: Lawrence Erlbaum.

GUIMARÃEs, E. (1978) Foco e pressuposição. In: Foco e pressuposição. Uberaba: Faculdades Integradas de Santo Tomás de Aquino, (4): 11-29.

HiRst, D. \& Di Cristo, D. (no prelo) A survey on intonation systems. Inédito. HoRvATH, J. (1986) Focus in the theory of grammar and the syntax of hungarian. Dordrecht: Foris Publications.

InKelas, S. \& ZeC, D., (orgs.) (1990) The Phonology-Syntax connection. Chicago: The University of Chicago Press.

JACKENDOFF, R. (1972) Semantic interpretation in Generative Grammar. Cambridge/Mass: The MIT Press.

KaIsSe, E. (1985) Connected speech: the interaction of Syntax and Phonology. Orlando: San Diego/Academic Press.

Liberman, M. \& , PrinCE, A. S. (1977) On stress and linguistic rhythm. Linguistic 
Inquiry, 8: 249-336.

Martins, A. (1992) Focos and clitics in European Portuguese. Papers at the Graduate Studies of Maryland. Maryland: University of Mariland, mimeo. Massini-Cagliari, G. (1995) Cantigas de amigo: do ritmo poético ao lingüístico: um estudo do percurso histórico da acentuação em Português. Tese de Doutorado em Lingüística. Campinas: UNICAMP/ IEL, mimeo.

NAPOLI, D. \& NeSPOR, M. (1979) The syntax of word initial consonant gemination in Italian. Language, 55 (1): 812-41.

Nespor, M. \& Vogel, I. (1986) Prosodic Phonology. Dordrecht: Foris Publications.

(1989) On clashes and lapses. Phonology, 6: 69-115.

PARTÉE, B. H. (1988) Quantification structures and compositionality. In: BACH,

E. et alii (orgs.) Quantification in natural languages. Dordrecht: Kluver Academic Press.

PrinCE, E. (1981) Toward a taxonomy of given/new information. In: Cole, P. (ed.) Radical Pragmatics. New York: Academic Press.

Rotenberg, J. (1987) The syntax of phonology. PhD Dissertation. Cambridge: MIT Press.

SElkirk, E. (1984) Phonology and syntax: the relations between sound and structure. Cambridge: The MIT Press.

(1995) Sentence prosody: intonation, stress and phrasing.In: GOLDSMITH, John A. (org.). The handbook of phonological theory. Oxford: Basil Blackwell, p. 550-69.

SelkiRK, E. \& Shen, T. (1990) Prosodic domains in Shangai Chinese. In: InKelas,

S. \& ZeC, D. (orgs.) The Phonology-Syntax connection. Chicago: University of Chicago Press, p. 313-37.

SoAREs, M. F. (1996) Aspectos da relação sintaxe-fonologia em Tikuna. Atas do 1o. Congresso Internacional da ABRALIN. Salvador: ABRALIN/ FINEP/UFBA, (1): 89-96.

TAGLicht, J. T. (1984) Message and emphasis. London/New York: Longmann. Vogel, I. \& KeneSeI, I. (1990) Syntax and semantics in phonology. InKeLAs, S. $\&$ Zec, D. (orgs.) The Syntax-Phonology connection. Chicago: Chicago University Press, p. 339-63.

ZeC, D. \& INKELAs, S. (orgs.) (1995) Syntax-phonology interface. In: GoldSMITH, J. A. (org.) The handbook of phonological theory. Oxford: Basil Blackwell, p. 535-49. 